\title{
Editorial: Synthesizing current research succinctly and elegantly
}

Ninety years ago the editor of the Physical Review, John T. Tate, proposed "a new type of journal in Physics-a journal in which would appear reports and critical comments on the various branches of current thought and research." He continues, "[w]e recognize the value of this kind of thing in so many ways - in the symposia we have at our meetings - in the seminars we hold in our research laboratories and universities. I would hope that this journal would extend the advantages of that sort of discussion to a much wider audience."

Endorsed by a few dozen prominent physicists, a supplement to the Physical Review was created, now known as Reviews of Modern Physics. Long before the arXiv, fax machines, and express mail, this was a timely way to disseminate and educate. The very first article, on the probable value of the physical constants by Raymond Birge in 1929, was the forerunner to the Particle Data Group's ongoing mission. Hans Bethe, with collaborators, published a series of review articles on nuclear physics in the 1930s that came to be known as the "Bethe bible." In 1948, Richard Feynman published his article on the path integral approach to quantum mechanics. Over the years, David Mermin has published any number of insightful reviews, and the list goes on. Articles that are over 50 years old are still a delight to read and can teach us much, from physics to pedagogy.

Why can't we replace this with video recorded lectures and disseminate ideas à la social media with hyperlinks serving up every definition and acronym, and routing us down every rabbit hole? Because good writing begets good reading, and good reading is a deliberate exercise, not a Sunday matinee. Joyce Carol Oates argues "that serious reading is as sacramental an act as serious writing..." (Oates, 1988). In a perfect world, everything we read and write would live up to this ideal.

Fortunately, Reviews of Modern Physics has been and remains a small, curated journal with about 11 articles per quarter: when the authors, referees, editors, and referees (the referees are very important and appreciated - two mentions may not be enough!) are giving their all, it is possible to aspire to this level of communication. Reviews of Modern Physics should be a pleasure to read on all levels: the articles should have strong and clear introductions to bring the reader up to speed; the content should not only be relevant but also elegantly and succinctly presented when possible; and there should be something for everyone in every issue.

Indeed, as the scope of APS expands through its membership, its publications, and its role in scientific outreach, Reviews of Modern Physics is taking steps to broaden the definition of "Modern Physics." We have appointed an editor to cover climate science, we are expanding to solicit articles on fluids, applications, and materials, and we continue to expand into new areas, "physics broadly construed." We have the distinct advantage that we are a journal that can plot our own course-we need not be swayed by the desire to promote our articles to the popular media and we can publish articles for our true constituents. Our sincere thanks go out to the authors, referees, and editors who continue to make this possible.

Randall Kamien

Randall D. Kamien is the Lead Editor of Reviews of Modern Physics and Vicki and William Abrams Professor in the Natural Sciences in the Department of Physics and Astronomy, University of Pennsylvania.

(This information also appears in APS News.)

For more on the history of Reviews of Modern Physics, see the February 2019 special issue of Physics Today (physicstoday.org).

At both the March and April Meetings this year, Reviews of Modern Physics will host special symposia to encourage excellent scientific communication, celebrate our 90th anniversary, and look forward to the Reviews of the Future.

APS March Meeting-Reviews of Modern Physics: The First 90 Years, Tuesday, March 5, 7:30-9 PM, Grand Ballroom A, Westin Boston Waterfront. For the latest information on the APS April Meeting sessions, see aps.org/meetings/april/ 
Randall Kamien: Editorials and Announcements

\section{REFERENCE}

Oates, Joyce Carol, 1988, "Literature as Pleasure, Pleasure as Literature," in Woman Writer: Occasions and Opportunities (Dutton, New York).

(Q) Published 13 February 2019

DOI: 10.1103/RevModPhys.91.010001 